\title{
TIBIAL POSTERIOR NERVE INJURY CAUSED BY BELOW-KNEE COMPRESSION STOCKING
}

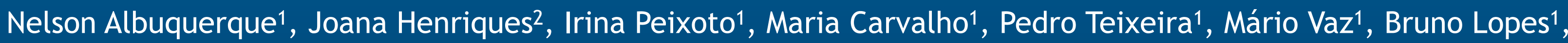
Tiago Felix ${ }^{1}$, Jorge Caldas ${ }^{1}$

1 Department of Physical and Rehabilitation Medicine of Centro Hospitalar

Tondela-Viseu - Viseu, Portugal

2 Primary care unit of São Pedro Do Sul - Viseu, Portugal

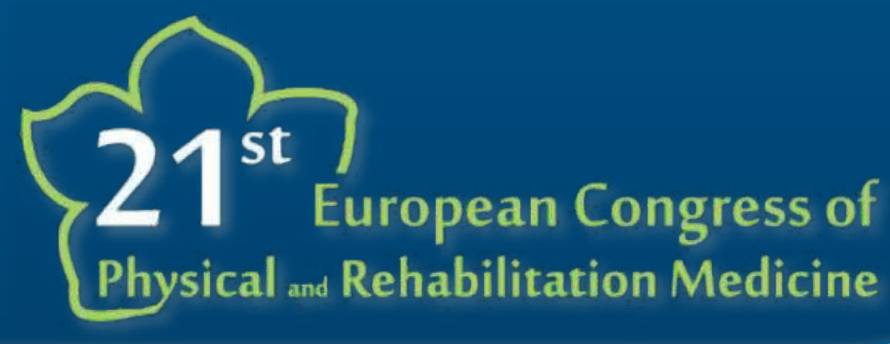

\section{Introduction:}

Peripheral mononeuropathies are one of the leading causes of access to health care. The diagnosis and location of peripheral nerve lesions depend mainly on the clinical history and the physical examination but sometimes is not enough.

\section{Case report}

70 years female, with type 2 diabetes, using elastic stockings, started pain in the popliteal region. It was later associated with low back pain and she was medicated with muscle relaxants, analgesics and NSAID.

However, she was observed by the PRM service for maintaining the pain which was irradiating to the posterior muscles of the leg and to the internal malleolus.

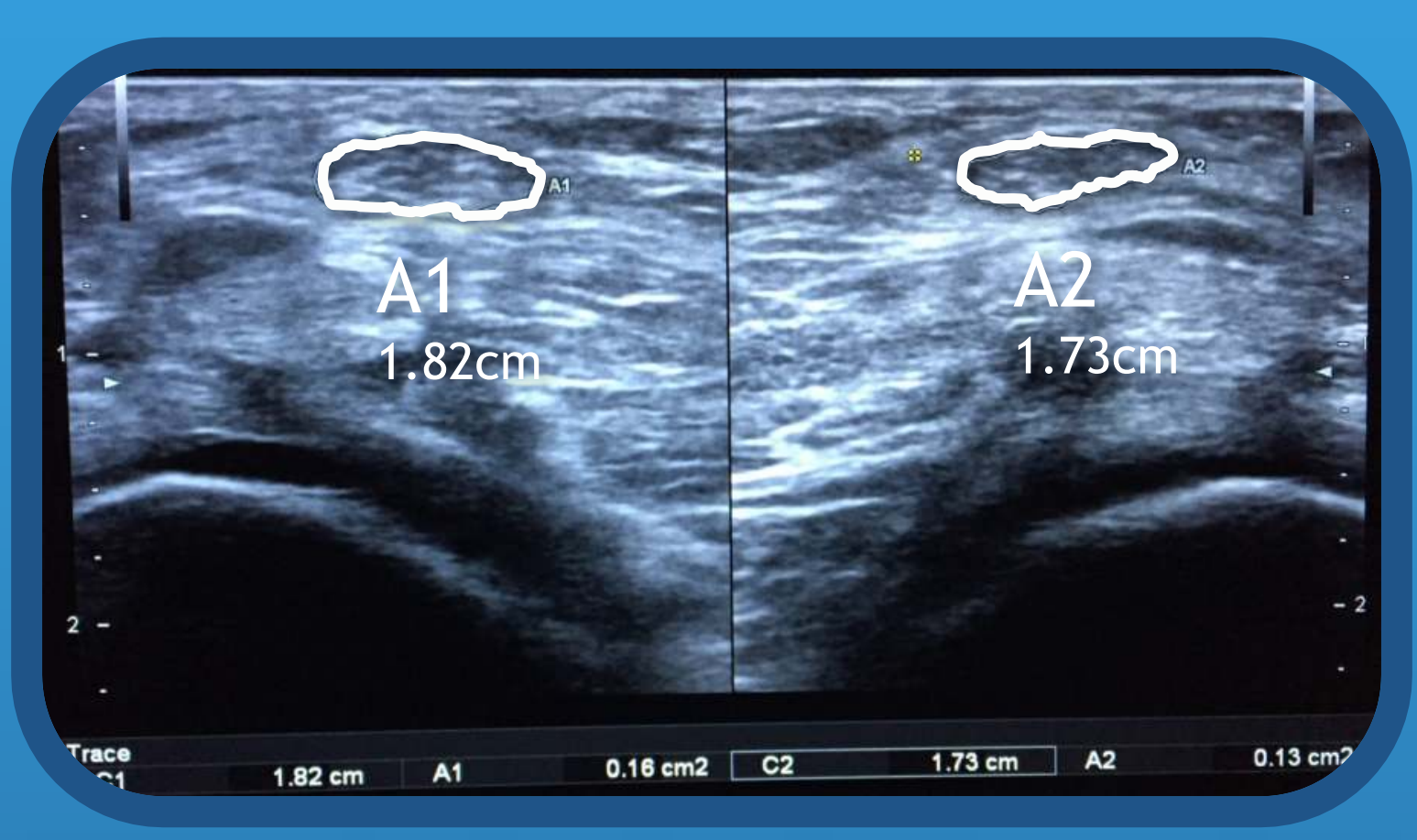

Ultrasound: Left tibial nerve after infiltration with lidocaine (A1) and the right tibial nerve (A2). At the bottom is visible both internal femoral condyles.

She had apparent pain in the palpation of the semitendinosus tendon but a Piriformis Syndrome was suspected due to muscle contracture and an electro-acupuncture session was performed.

Nonetheless, the patient maintained the pain and an ultrasound scan was executed. The ultrasound probe increased the symptoms when pressing the posterior tibial nerve which was very superficial (a variant of the normal). This nerve had an increased dimension in comparison to the contralateral one and a positive Tinel's sign. A local infiltration was performed with $1.5 \mathrm{cc}$ of $1 \%$ Lidocaine which lead to the regression of the symptoms.

\section{Discussion:}

There were several factors that contributed to this clinical presentation, first, the characteristics of the antalgic gait that was probably the activator factor of the piriformis muscle syndrome, second, the compression caused by the elastic stockings on the tibial nerve, and finally the predisposition of the nerve to injury, either by its anatomical variation or by type 2 Diabetes Mellitus.

\section{Conclusion}

This case highlights the importance of having a good clinical history combined with a detailed physical examination associated with the ultrasound scan in order to complement the data collected as much as possible to reach the diagnostic key.

Hanewinckel R, Ikram MA, Van Doorn PA. Peripheral Neuropathies. Vol 138. 1st ed. Elsevier B.V.; 2016. doi:10.1016/B978-0-12-802973-2.00015-X.

Bencardino JT, Delaney H. Entrapment neuropathies of the lower extremity. Musculoskelet Dis 2013-2016 Diagnostic Imaging Interv Tech. 2013;5(5):181-193. doi:10.1007/978-88-470-5292-5_24.

Padua L, Di Pasquale A, Liotta G, et al. Ultrasound as a useful tool in the diagnosis and management of

traumatic nerve lesions. Clin Neurophysiol. 2013;124(6):1237-1243. doi:10.1016/j.clinph.2012.10.024.

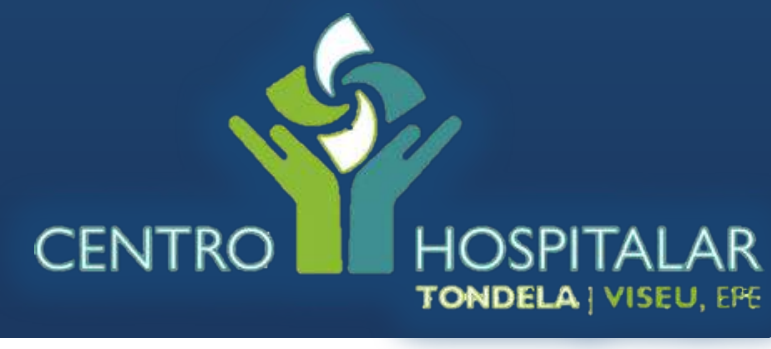

